\title{
Penetration of Tenofovir and Emtricitabine in Mucosal Tissues: Implications for Prevention of HIV-1 Transmission
}

\author{
Kristine B. Patterson ${ }^{1}$, Heather A. Prince ${ }^{1}$, Eric Kraft ${ }^{2,{ }^{*}}$, Amanda J. Jenkins ${ }^{2, \dagger}$, Nicholas J. \\ Shaheen ${ }^{1}$, James F. Rooney ${ }^{3}$, Myron S. Cohen ${ }^{1}$, and Angela D. M. Kashuba ${ }^{2, \neq}$ \\ ${ }^{1}$ University of North Carolina School of Medicine, Chapel Hill, NC 27599, USA \\ 2University of North Carolina Eshelman School of Pharmacy, Chapel Hill, NC 27599, USA \\ ${ }^{3}$ Gilead Sciences, Foster City, CA 94404, USA
}

\section{Abstract}

A mainstay of strategies to prevent HIV-1 transmission is to use antiretroviral therapy (ART) for pre-exposure prophylaxis (PrEP). Critical to the design and interpretation of PrEP prevention trials is the ability to make accurate pharmacological measurements of ART drugs in human genital and colorectal mucosal tissues, the principal route of HIV transmission. Here, we evaluated two drugs that are preferentially used for PrEP: tenofovir (TFV) disoproxil fumarate (TDF) and emtricitabine (FTC). A single oral dose of TDF/FTC (Truvada) was administered to 15 healthy individuals. Over the next 14 days, TFV and FTC were measured in blood plasma and genital secretions using a sensitive assay (lower level of quantification, $0.1 \mathrm{ng} / \mathrm{ml}$ ). The active intracellular phosphorylated metabolites of these drugs [TFV diphospate (TFV-DP) and FTC triphosphate (FTC-TP)] were measured in homogenates prepared from rectal, vaginal, and cervical tissues. TFV and FTC were detected in blood plasma 14 days after administration of a single dose. The area under the concentration-time curve from 24 hours to 14 days $\left(\mathrm{AUC}_{1-14 \mathrm{~d}}\right)$ for FTC in genital secretions was 27 -fold greater than in blood plasma, whereas the $\mathrm{AUC}_{1-14 \mathrm{~d}}$ for TFV was only 2.5 -fold greater in genital secretions than in blood plasma. In rectal tissue, TFV and TFV-DP concentrations were detectable for 14 days and were 100-fold higher than the concentrations in vaginal and cervical tissues. Vaginal and cervical tissue concentrations of FTC were 10- to 15-fold higher than in rectal tissue. Despite high concentrations of FTC in vaginal and cervical tissue, FTC-TP concentrations in all tissue types were detected for only 2 days after dose. The exposure to TFV, TFV-DP, FTC, and FTC-TP was wide ranging depending on the type of mucosal tissue. These results demonstrate the need for detailed pharmacological studies to improve the application of ART for PrEP to prevent transmission of HIV.

Copyright 2011 by the American Association for the Advancement of Science; all rights reserved.

†To whom correspondence should be addressed. akashuba@unc.edu.

*Present address: GlaxoSmithKline, Research Triangle Park, NC 27709, USA.

$\dagger$ Present address: United Therapeutics, Research Triangle Park, NC 27709, USA.

Author contributions: K.B.P., M.S.C., J.F.R., and A.D.M.K. conceived and designed the experiments. H.A.P., A.J.J., and N.J.S. coordinated and collected all specimens. E.K. developed the analytic method and analyzed the specimens. K.B.P. and A.D.M.K. analyzed the data. K.B.P., J.F.R., M.S.C., and A.D.M.K. created the oral presentation of some of these data for the XVIII International AIDS Conference, Vienna, Austria, 18 to 23 July 2010. K.B.P., M.S.C., and A.D.M.K. wrote the paper. All authors reviewed the paper.

Competing interests: J.F.R. is an employee of Gilead Sciences; A.D.M.K. is a paid consultant to Gilead. Patents related to the drugs TDF and FTC are held by Gilead. J.F.R. is coinventor on pending patent PCT/US2011/39505 "Topical Antiviral Formulations." The other authors declare that they have no competing interests.

Accession numbers: The following reagents were obtained through the AIDS Research and Reference Reagent Program, Division of AIDS, National Institute of Allergy and Infectious Diseases, NIH: tenofovir and emtricitabine. 


\section{INTRODUCTION}

The HIV epidemic is driven by sexual transmission. An estimated 2.9 million individuals acquired HIV in 2009 despite a global increase in access to antiretroviral therapy (ART) (1). About 7000 new infections occur each day worldwide, outstripping the expansion of treatment availability (1), the decrease in AIDS-related mortality (2), and the decrease in perinatal transmission (3).

In the last year, the results from several pre-exposure chemopro-phylaxis (PrEP) intervention trials with ART have demonstrated that PrEP is one approach for preventing HIV infection. In the CAPRISA 004 trial, the first of these studies, the use of $1 \%$ tenofovir (TFV) gel reduced HIV acquisition in women by $39 \%$ (4). This trial was followed by the Pre-exposure Prophylaxis Initiative (iPrEx) study, in which the daily use of an oral fixeddose combination of tenofovir disoproxil fumarate and emtricitabine (TDF/FTC; Truvada) reduced HIV acquisition by $44 \%$ in men who have sex with men (5). In both of these studies, there was a strong relationship between local exposure to ART in the genital tract (CAPRISA 004) (6) or systemic exposure via plasma (iPrEx) (7) and reduced HIV acquisition. Two additional studies, TDF2 (8) and Partners PrEP (9), have demonstrated 67 to $78 \%$ protection against HIV acquisition in men and women when daily TDF with or without FTC is used. However, a similar trial in women using daily dosing with Truvada (FEM-PrEP) was halted because substantial HIV prevention (that is, >30\%) could not be demonstrated (10). In the Vaginal and Oral Interventions to Control the Epidemic (VOICE) trial, the oral TDF (without FTC) arm was stopped by the Data Safety and Monitoring Board because protection from HIV infection was not observed (11). The vastly different outcomes in these prevention trials, which used identical antivirals and dosing schedules, have many potential explanations. These agents cannot prevent HIV infection unless critical concentrations of active metabolites of the ART drugs are achieved in body fluids and in vulnerable mucosal tissues where HIV-1 infection occurs.

The current study was undertaken for two purposes. First, we wanted to determine the decay of TFV and FTC over 14 days after a single oral dose, which mimics an intermittently used dosing strategy before or after sexual intercourse. We aimed to measure the decay of TFV and FTC in plasma, genital fluids, and genital mucosal tissues to gain insight into dosing strategies based on sexual practices. There is considerable concern that in some of the PrEP studies, poor adherence to the daily dosing regimen contributed to the failure of some of the trials. Second, we wanted to examine the pharmacokinetics (PK) of ART prodrugs and their active phosphorylated forms in body fluids and vulnerable mucosal tissues.

\section{RESULTS}

\section{Subject demographics}

Eight male and seven female healthy individuals were enrolled in the study and provided the required tissue and fluid samples (see Table 1 for subject demographics). The median age of the male and female subjects was 26 and 22 years, respectively. The median body mass index (BMI) was $23.5 \mathrm{~kg} / \mathrm{m}^{2}$ for the males and $24.8 \mathrm{~kg} / \mathrm{m}^{2}$ for the females. Five of the males and six of the females were Caucasian. All participants tolerated the study medication without any adverse events. Bleeding associated with the biopsy procedures was minimal and was controlled at the completion of the biopsy procedure.

Table 2 summarizes the concentrations of TFV and FTC and phosphorylated forms of these drugs [TFV diphospate (TFV-DP) and FTC triphosphate (FTC-TP), respectively] in each tissue or fluid at 24 hours after a single oral dose of Truvada $\left(C_{24 \mathrm{~h}}\right)$. Table 2 also shows the area under the concentration-time curve from 24 hours to 14 days $\left(\mathrm{AUC}_{1-14 \mathrm{~d}}\right)$ calculated 
using noncompartmental linear/logarithmic trapezoidal methods. Figures 1 to 3 illustrate drug concentrations (median values) over time in six tissues and fluids measured by liquidchromatography and mass spectroscopy methods. No cervicovaginal fluid and semen samples had any below level of quantification (BLQ) values that required imputing (estimating) for any analyte. Twelve percent of plasma samples, $1 \%$ of rectal tissue, $7 \%$ of cervical tissue, and $15 \%$ of vaginal tissue samples were imputed for one to two analytes.

\section{Drug concentrations in body fluids and mucosal tissues}

Blood plasma-To detect TFV and FTC concentrations for 36 hours after dosing $(5,12)$, we developed an assay with 100-fold greater sensitivity than other published methods. Using this assay, we were able to detect TFV and FTC concentrations in blood plasma up to 14 days after dose in all subjects (see Fig. 1A and Materials and Methods).

The median $\mathrm{AUC}_{1-14 \mathrm{~d}}$ for TFV and FTC was 91 and $83 \mathrm{ng} \cdot$ days $/ \mathrm{ml}$, respectively. The median terminal elimination half-life $\left(t_{1 / 2}\right)$, calculated from 7 to 14 days, was 47 hours for TFV and 49 hours for FTC. Bi-exponential elimination is illustrated in Fig. 1A, with one elimination rate occurring between 1 and 5 days after dose, and a second occurring between 7 and 14 days after dose.

Cervicovaginal fluid-Concentrations of TFV and FTC in cervicovaginal fluid over 14 days after a single dose are shown in Fig. 1B. These concentrations are similar to our previous measurements with single and daily dosing in HIV-positive women (13). The $\mathrm{AUC}_{1-14 \mathrm{~d}}$ for TFV and FTC in cervicovaginal fluid was 251 (151 to 1257) and 2445 (2309 to 3631) ng.days/ml, respectively. Compared with TFV, the concentrations of FTC were much higher throughout the study period. The $\mathrm{AUC}_{1-14 \mathrm{~d}}$ ratio of cervicovaginal fluid to blood plasma for TFV was 2.6 (1.7 to 13.4), whereas for FTC it was 26.8 (25.0 to 43.8). This demonstrates that FTC concentrations remained high in female genital tract secretions throughout all time intervals after dosing. The terminal elimination half-life $t_{1 / 2}$ of FTC in cervicovaginal fluid was 40 hours, which was similar to that observed in blood plasma. In comparison, the terminal elimination half-life $t_{1 / 2}$ for TFV in cervicovaginal fluid was 71 hours, which is about $50 \%$ longer than that in blood plasma.

Seminal plasma-We measured TFV and FTC concentrations in seminal plasma to elucidate drug behavior in the male genital tract. Concentrations of TFV and FTC in seminal plasma are shown in Fig. 1C. TFV concentrations were similar to our previous measurements with single and daily dosing in HIV-positive men (13). The $\mathrm{AUC}_{1-14 \mathrm{~d}}$ of TFV and FTC in seminal plasma was 91 (51 to 156 ) and 408 (233 to 586) ng.days $/ \mathrm{ml}$, respectively. As with cervicovaginal fluid, the seminal plasma concentrations of FTC were much higher than those of blood plasma throughout the study period. The $\mathrm{AUC}_{1-14 \mathrm{~d}}$ ratio of seminal plasma to blood plasma for TFV was 1.0 (0.6 to 1.4) and for FTC was 4.5 (3.3 to 6.1). The terminal elimination half-life $t_{1 / 2}$ for TFV and FTC in seminal plasma was similar to that in blood plasma: 59 and 47 hours, respectively.

Genital mucosal tissues-Once inside mucosal epithelial cells, TFV and FTC are phosphorylated to their active metabolites, TFV-DP and FTC-TP, respectively. The tissue concentrations for TFV and TFV-DP are shown in Fig. 2, A and B, and for FTC and FTC$\mathrm{TP}$ are shown in Fig. 3, A and B. Composite PK parameters of $C_{24 \mathrm{~h}}$ and $\mathrm{AUC}_{1-14 \mathrm{~d}}$ are listed in Table 2.

Rectal tissue-TFV and TFV-DP were both detectable in rectal tissue throughout the 14day study period. The $\mathrm{AUC}_{1-14 \mathrm{~d}}$ for TFV was $2989 \mathrm{ng}$.days/g, resulting in a 34-fold increase in rectal tissue concentration compared with the concentration in blood plasma. The 
AUC $_{1-14 \mathrm{~d}}$ of TFV-DP was 649,502 fmol-days $/ \mathrm{g}$. The median concentration of TFV-DP in rectal tissue homogenates at the end of the first 24-hour period after dosing was 206,950 fmol/g, demonstrating high penetration of this drug into this mucosal site. In these rectal tissue homogenates, there was a strong log-linear relationship between TFV and TFV-DP concentrations $\left(I^{2}=0.86 ; P<0.01\right)$. FTC could also be detected in rectal tissue throughout the 14-day study period. However, the FTC concentration in the rectum was substantially lower than that for TFV, with a median concentration at 24 hours $\left(C_{24 \mathrm{~h}}\right)$ of $124 \mathrm{ng} / \mathrm{g}$ and an AUC $_{1-14 d}$ of $266 \mathrm{ng}$.days/g. FTC-TP (Fig. 3B) was only detected in rectal tissue for 2 days after dosing. The relationship between FTC and FTC-TP concentrations in this tissue could not be calculated.

Vaginal tissue-In the female subjects, TFV was detectable in vaginal tissue for up to 10 days after a single dose of Truvada, whereas TFV-DP was detected for the 14 days of the study. Twenty-four hours after dosing, the median TFV concentration in vaginal tissue was about 2.5 logs lower than the median TFV concentration in rectal tissue (6.8 versus $1877 \mathrm{ng} /$ $\mathrm{g}$ ), and the TFV-DP concentrations were about 2.2 logs lower (1645 versus 206,950 fmol/g).

FTC could be measured for up to 10 days in vaginal tissue and exceeded the blood plasma FTC concentration by sevenfold. FTC-TP could only be detected in vaginal tissue 24 to 48 hours after the oral dose was given. At 24 hours after dose, the median FTC concentration in vaginal tissue was about $50 \%$ lower than in rectal tissue (63 versus $126 \mathrm{ng} / \mathrm{g}$ ), and the FTCTP concentration was about one log higher than in rectal tissue $(63,469$ versus $8450 \mathrm{fmol} / \mathrm{g})$.

Cervical tissue-TFV and FTC concentrations in cervical tissue were similar to, but more variable than, the drug concentrations in vaginal tissue. Similar to vaginal tissue, FTC could be quantified in cervical tissue for up to 10 days after dosing. The $\mathrm{AUC}_{1-14 \mathrm{~d}}$ for FTC was $2495 \mathrm{ng} / \mathrm{g}$, which was four times greater than that for TFV. Similar to vaginal and rectal tissue, FTC-TP could only be measured in cervical tissue for the first 24 hours after dosing. Because of a large proportion of undetectable TFV-DP and FTC-TP concentrations in cervical and vaginal tissues, the relationship between TFV or FTC and their intracellular metabolites could not be calculated.

\section{DISCUSSION}

Antiretroviral drugs when given prophylactically have the potential to prevent the acquisition of HIV (14). Pre-exposure chemoprophylaxis (PrEP) using TDF with or without FTC decreases HIV acquisition in animal models when used topically and orally (15-18), in women when used topically (4), and in men who have sex with men when used orally (5). However, in two recent trials-using daily doses of TDF combined with FTC (Truvada) in the FEM-PrEP trial or daily doses of TDF alone in one arm of the VOICE trial-there was failure to protect women from acquiring HIV $(10,11)$. In contrast, the Partners PrEP trial in serodiscordant couples demonstrated 62 and $73 \%$ protection with either TDF alone or in combination with FTC, respectively (9). Last, the TDF2 trial using a daily oral dose of TDF combined with FTC strongly suggested differential protection based on gender, although the study was not powered to evaluate gender differences (8). The reason for the different outcomes of these trials is not known. However, it is possible that differential penetration and half-life of the antiretroviral agents in different mucosal tissues did not lead to equivalent protection among all mucosal tissues exposed to HIV, permitting HIV acquisition in some cases.

We studied the concentrations of TFV, FTC, and their active metabolites in mucosal tissues, genital secretions, and blood plasma after a single oral dose of the fixed-dose drug combination TDF/FTC (Truvada) using an ultrasensitive assay (100-fold more sensitive than 
standard published methods) (19-21). Previous work has carefully examined the PK profiles of TFV and FTC and their active metabolites in the first 24 hours after dosing $(13,22)$. Therefore, in our study, sampling began at the 24-hour time point to define the final phase of decay. We determined that TFV and FTC plasma concentrations could be detected in all subjects, and quantified in 50\% of subjects for 14 days after a single dose of Truvada. The terminal elimination half-life was 47 hours for TFV and 49 hours for FTC between 7 and 14 days after dosing. These are longer than the 17- and 10-hour terminal elimination half-life times usually cited for TFV and FTC, respectively (23). Our results may more accurately reflect the true terminal elimination half-life of the drugs from plasma, because the shorter half-lives cited in the literature were derived from concentrations measured for up to only 48 hours after dosing. The longer drug elimination half-lives reported here also suggest that there may be a longer-lived cell population that forms a slowly equilibrating reservoir of drug. For example, the natural destruction of peripheral blood mononuclear cells (PBMCs) may release TFV-DP and FTC-TP into the systemic circulation, where these drug metabolites could be converted back to the parent TFV and FTC drugs. We did not measure PBMC concentrations in this study, but this could be explored further in future studies. The long plasma half-lives of TFV and FTC do not help to explain the inconsistent results among the different PrEP trials.

We report here that the concentrations of TFV and FTC and their respective active metabolites TFV-DP and FTC-TP varied according to the mucosal tissue type. The TFV concentration in rectal mucosa was greater and existed longer than the FTC concentration, whereas the FTC concentration in vaginal and cervical tissue was greater than the TFV concentration. This differential penetration may provide insight into the variable level of protection reported with different PrEP drug combinations in diverse populations in the different trials. TFV, TFV-DP, and FTC could be quantified in mucosal tissues for 10 to 14 days, whereas FTC-TP was only detected for up to 2 days. Data generated during the development and validation of the assay for detecting TFV, FTC, and their active metabolites did not suggest that FTC-TP was degraded during tissue processing (18). Therefore, we propose that FTC-TP (23) has a shorter tissue half-life than does TFV-DP $(23,24)$. The reason for the shorter half-life of FTC-TP could be elucidated if the ART drugs were studied in individual cell populations, which we did not do here because this would have required quantities of tissue that could not be obtained in a clinical study.

Concentrations of TFV, FTC, TFV-DP, and FTC-TP in human rectal mucosa have not previously been evaluated (25). The TFV results presented here have been confirmed in two recently completed trials (MTN 001 and MTN 006) $(26,27)$. The prolonged high concentration of TFV and its active metabolite TFV-DP in rectal tissues is consistent with the benefit provided by TFV in the rectal challenge macaque model (15) and the iPrEx clinical trial in human subjects (5). The more limited concentrations of FTC and its metabolite FTC-TP in the rectal mucosa may explain the limited protective effects of FTC in the macaque model (15).

The penetration of ART into seminal plasma and vaginal and cervical tissues, although comparable or superior to penetration in blood plasma, was 10 to 100 times lower than penetration of rectal tissue. Our earlier reports from studies of single and daily dosing of TDF and FTC in semen (22) and cervicovaginal fluids (13) yielded similar results. Limited vaginal challenge studies in macaques and humanized mice $(28,29)$ demonstrated partial to complete efficacy with TFV \pm FTC treatment. However, there is a paucity of data regarding genital tract tissue concentrations of ART drugs in these preclinical animal model systems. The failure of daily oral ART to prevent HIV acquisition in the FEM-PrEP and VOICE trials raises the possibility that the concentrations of TFV and FTC in animal studies may be different from those achieved in humans, and that the concentrations achieved in humans are 
not sufficient to prevent HIV acquisition. The differing results of these trials also reinforce the need for in-depth preclinical pharmacological analyses to establish biological plausibility before beginning large-scale clinical studies.

The concentrations of ART achieved in female genital tract tissue, reported here and in our previous studies (13), suggest that standard TDF/FTC oral dosing may not be sufficient to prevent HIV acquisition. In the CAPRISA 004 study, TFV concentrations in the vaginal lumen 24 hours after coitally dependent dosing were estimated to be about $10^{5} \mathrm{ng} / \mathrm{ml}$, which would result in TFV-DP concentrations of $10^{2}$ to $10^{3} \mathrm{fmol} / \mathrm{mg}$ based on vaginal and cervical biopsy data from this study and others $(6,17,30,31)$. These TFV-DP concentrations are 100 times greater than what we observed in vaginal and cervical tissue after oral dosing (but are similar to what we observed in rectal tissue) (6). Finally, recent clinical data on the shedding of HIV RNA in the genital tract of women may also provide some indirect evidence of ART activity in mucosal tissue. More than 50\% of HIV-infected women on ART (including two nucleoside reverse transcriptase inhibitors) with undetectable HIV RNA in their blood plasma had detectable HIV RNA in their genital secretions (32). The ART regimens are too variable in these cohorts to isolate the effect of individual drugs or select combination regimens based on local HIV replication. However, these data suggest that some ART drugs may not achieve sufficient concentrations in mucosal tissues to completely suppress local replication of HIV and, accordingly, may not be sufficient to prevent acquisition of HIV.

Our study provides new insights into using ART for PrEP to prevent HIV infection. Vaginal acquisition of HIV may require a stronger barrier to infection than that provided by oral dosing with a TDF/FTC combination. The results of the current study and recent PrEP clinical trials indicate that more work needs to be done to elucidate the appropriate pharmacological barrier required to prevent HIV acquisition. More detailed pharmacological studies are required to better evaluate whether ART can prevent HIV acquisition and for the optimal management of HIV prevention trials that use antiviral agents prophylactically to prevent HIV infection.

\section{MATERIALS AND METHODS}

\section{Study design and subject selection}

This 14-day, open-label, PK study in healthy HIV-negative female and male volunteers was conducted between October 2008 and May 2010 at the University of North Carolina at Chapel Hill (UNC). The UNC Biomedical Institutional Review Board approved the study, and all subjects provided written informed consent before any study procedure (ClinicalTrials.gov identifier NTC00080410). Subjects were eligible to participate if they were healthy, were between the ages of 18 and 50 years, and had a BMI between 18 and 30 $\mathrm{kg} / \mathrm{m}^{2}$ with a total body weight of $250 \mathrm{~kg}$. Females were required to be premenopausal with regular menstrual cycles (between 26 and 35 days), have an intact uterus and cervix, and not be pregnant or breastfeeding. Males were required to not participate in a conception process. Subjects were excluded on the basis of any evidence of kidney disease; a positive urine drug screen; the presence of a sexually transmitted infection; or infection with HIV, hepatitis B virus, or hepatitis $\mathrm{C}$ virus. Subjects were excluded for any abnormal screening laboratory results, any clinically significant abnormality on physical examination, or any clinical condition that would interfere with study procedures. Subjects were required to stop all medications 7 days before and herbal supplements 14 days before study medication administration, and medications could not be restarted until study completion. Females were required to be off hormonal contraceptives for a minimum of 30 days or depomedroxyprogesterone for 120 days before enrollment. Subjects were limited to five cigarettes per day and were allowed up to $1 \mathrm{~g}$ of acetaminophen per day. Subjects were 
instructed to abstain from sexual intercourse and the use of intravaginal (females) or intrarectal (males) devices from 72 hours before dosing until study discharge.

Screening procedures occurred within the 28 days before study medication dosing. Comprehensive laboratory studies, including a complete blood count with differential, liver function tests, serum chemistries, hepatitis B and C virus serology panels, urinalysis, and serum pregnancy testing, and sexually transmitted infection evaluations were performed at the screening visit. Sexually transmitted infection evaluations included testing for gonorrhea, Chlamydia, trichomonas (Aptima Combo 2 and Aptima TV ASR Kits; GenProbe Inc.), and syphilis. Herpes simplex virus type 2 antibody (Focus Diagnostics) was measured if indicated by the presence of suspected herpetic lesions on exam. All subjects underwent anonymous HIV testing with a standard HIV-1/2 ELISA (enzyme-linked immunosorbent assay) (Genetic Systems HIV-1/HIV-2 Plus O EIA) with pooled HIV-1 polymerase chain reaction (PCR) testing (Roche COBAS AmpliPrep/COBAS TaqMan HIV-1 Test, v.1.0). All testing was performed in the McLendon Laboratories of UNC Hospitals or in the UNC Sexually Transmitted Diseases Cooperative Research Center Microbiology Core Lab.

\section{Study visits}

Subjects received a single dose of $300 \mathrm{mg}$ of TDF and $200 \mathrm{mg}$ of FTC administered as a single-dose tablet of Truvada in the morning of the baseline study visit. All subjects had paired blood plasma and cervicovaginal fluid or semen collected on days 1, 2, 5, 7, 10, and 14 after dose. Subjects were sequentially assigned to undergo mucosal tissue biopsy on days 1 and 5, 2 and 10, or 7 and 14 after dose (two men and two women at each time point). All mucosal tissue collection procedures were performed in the outpatient setting. Females underwent two cervical and two vaginal biopsies at each of the two paired time points. Males underwent lower gastrointestinal (about $10 \mathrm{~cm}$ from anal verge) biopsies at each of the same two paired time points. Males were requested to follow a low-fiber diet for 3 days before biopsy dates and a clear liquid diet for 12 hours before the procedure.

\section{Sample collection}

Blood plasma-Whole blood was obtained with EDTA collection tubes (BD Diagnostics) and centrifuged at $1300 \mathrm{~g}$ at $4^{\circ} \mathrm{C}$ for $10 \mathrm{~min}$. The resulting blood plasma was aliquoted into labeled cryovials and stored at $-80^{\circ} \mathrm{C}$ until analysis.

Vaginal and cervical specimens-Clinicians collected cervicovaginal fluid samples via direct aspiration with a volumetric aspiration device (13) before speculum insertion. After collection, cervicovaginal fluid was transferred to labeled cryovials and stored at $-80^{\circ} \mathrm{C}$ until analysis.

Vaginal and cervical tissues were collected by biopsy. Briefly, subjects were placed in the dorsal lithotomy position. After speculum insertion, the vaginal fornices and the entire cervix were prepped with $2 \%$ viscous lidocaine solution (lidocaine hydrochloride), and then were additionally anesthetized with topical $20 \%$ benzocaine spray (HurriCaine, Beutlich Pharmaceuticals). Vaginal tissue biopsies were obtained at either the left or the right vaginal fornix. Cervical biopsies were obtained at either the 3- or the 9-o'clock position. Biopsies at the second time point were obtained at the opposite location. About $3 \mathrm{~mm} \times 3 \mathrm{~mm} \times 1 \mathrm{~mm}$ specimens were obtained at both the vaginal and the cervical sites with Baby Tischler forceps (Cooper Surgical). Samples were placed in separate labeled screw-capped polypropylene tubes, immediately snap-frozen in liquid nitrogen, and stored at $-80^{\circ} \mathrm{C}$ until analysis. 
Seminal plasma and rectal tissue-Semen samples were collected in the research center. Whole semen samples were allowed to liquefy at room temperature for at least 45 min before centrifugation at $2500 \mathrm{~g}$ at $10^{\circ} \mathrm{C}$ for $15 \mathrm{~min}$. Seminal plasma was transferred to labeled cryovials and stored at $-80^{\circ} \mathrm{C}$ until analysis. Rectal tissue samples were obtained through flexible sigmoidoscopy at one of the UNC Gastrointestinal (GI) Procedure Suites according to standard GI procedures. Conscious sedation was offered but declined by all participants. Once biopsy sites were identified, the sites were rinsed with sterile irrigation water with diluted simethicone oral drops before collection. Ten single rectal tissue biopsies were collected with Radial Jaw 4 Large Capacity Forceps (Boston Scientific), pooled into a single cryovial, and immediately snap-frozen in liquid nitrogen. All specimens were stored at $-80^{\circ} \mathrm{C}$ until analysis.

\section{Sample processing}

TFV and FTC were extracted from $70 \mu 1$ of blood plasma and $50 \mu 1$ of cervicovaginal fluid or seminal plasma with acetonitrile protein precipitation. TFV, TFV diphosphate (TFV-DP), FTC, and FTC-TP were extracted from tissue samples with a protein precipitation and homogenization process on a Precellys 24 tissue homogenizer (Bertin Technologies). Individual cell populations were not isolated from the tissue. Internal standards were isotopically labeled TFV and FTC for the protein precipitation of blood plasma, cervicovaginal fluid, and seminal plasma. Isotopically labeled TFV-DP and FTC-TP were also used as internal standards for tissue analysis. Samples were analyzed on an Agilent 6460 triple quadruple liquid chromatography-tandem mass spectrometry (LC-MS/MS) system (Agilent Technologies) with electrospray ionization. The ion transition for TFV was $288+$ to $176+$, the ion transition for FTC was $248+$ to $130+$, the transition for TFV-DP was $448+$ to $270+$, and the ion transition for FTC-TP was 488+ to 130+. Blood plasma, cervicovaginal fluid, and seminal plasma analytes were separated on a reversed-phase Waters Atlantis T3 C18 $(2.1 \times 100 \mathrm{~mm}, 3 \mu \mathrm{m})$ high-performance liquid chromatography (HPLC) column with an isocratic mobile phase of $2.5 \% \mathrm{MeCN}$ with $0.1 \%$ formic acid/ $97.5 \%$ water with $0.1 \%$ formic acid and a flow rate of $0.3 \mathrm{ml} / \mathrm{min}$ with a column temperature of $35^{\circ} \mathrm{C}$. Tissue analytes were separated on a Waters Xbridge C18 $(2.1 \times 20 \mathrm{~mm}, 5 \mu \mathrm{m})$ column in series with a Thermo Scientific BioBasic AX $(50 \times 2.1 \mathrm{~mm}, 5 \mu \mathrm{m})$ column. Having the columns in series provided a mixed-mode reverse phase and ion exchange separation to simultaneously quantify phosphorylated and unphosphorylated analytes. An initial mobile phase of $20 \mathrm{mM}$ ammonium acetate went to $100 \%$ (40\% acetonitrile/60\% 100 $\mathrm{mM}$ ammonium acetate, $\mathrm{pH} 9.45$ ) over a period of $2 \mathrm{~min}$. The mobile phase was then held at $100 \%$ (40\% acetonitrile/60\% $100 \mathrm{mM}$ ammonium acetate, $\mathrm{pH} 9.45$ ) for an additional 3.2 $\mathrm{min}$. The columns were then recovered in $20 \mathrm{mM}$ ammonium acetate for $6.5 \mathrm{~min}$. The flow rate for the method was $0.3 \mathrm{ml} / \mathrm{min}$ with a column compartment temperature of $35^{\circ} \mathrm{C}$. The analytical concentration range for TFV and FTC in blood plasma was 0.1 to $500 \mathrm{ng} / \mathrm{ml}$, and in cervicovaginal fluid and seminal plasma was 2 to $1000 \mathrm{ng} / \mathrm{ml}$. TFV, TFV-DP, FTC, and FTC-TP concentration ranges in tissue were 0.1 to $1000 \mathrm{ng} / \mathrm{ml}$. Standards, quality controls (QCs), and blanks for cervicovaginal fluid, seminal plasma, blood plasma, and biopsy samples were prepared with equivalent blank matrix obtained from external suppliers and UNC Hospital donors. All blank material was obtained from screened donors that were free of drugs that could potentially interfere with assay results. Blank samples were evaluated for analyte signals and compared to lower level of quantification (LLOQ) response to assess contamination of sample preparation media and matrices. Inspection of blanks allowed each sample assay to be examined for sources of contamination that would affect LLOQ accuracy.

Two separately prepared standard curves were used to bracket all samples, QCs, and blanks. QC samples at three concentration levels representing the low, middle, and high end of the 
calibration curve were distributed among the samples and blanks to ensure accurate quantitation throughout the analysis. Acceptance criteria for the assay were based on those from the Food and Drug Administration (FDA) for bioanalytical assays. QC concentrations had to calculate to $\pm 15 \%$ of their nominal value to be accepted. Standard concentrations were back-calculated from the calibration regression and their values had to be $\pm 15 \%$ from their nominal concentration, with the exception of the LLOQ, which required $\pm 20 \%$. In order for sample concentration values to be reported, $75 \%$ of all standards and $66 \%$ of all QCs had to be acceptable. For vaginal biopsies, FTC QCs had an average $( \pm$ SD) accuracy of $102.0 \pm 7.5$, TFV had an average accuracy of $98.4 \pm 6.5$, TFV-DP had an average accuracy of $105.0 \pm 7.2$, and FTC-TP had an average accuracy of $94.2 \pm 5$. For cervical biopsies, FTC, TFV, FTC-TP, and TFV-DP QCs had accuracies of 102.4 $\pm 7.0,100.0 \pm 8.4,100.2 \pm$ 5.8 , and $99.7 \pm 12.3$, respectively. For rectal biopsies, FTC, TFV, FTC-TP, and TFV-DP QCs had accuracies of $97.5 \pm 6.8,98.6 \pm 7.3,103.4 \pm 11.1$, and $100.4 \pm 5.6$, respectively. Cervical biopsy samples weighed 5 to $17 \mathrm{mg}$, vaginal biopsy samples weighed 1 to $30 \mathrm{mg}$, and rectal tissue biopsy samples weighed 11 to $33 \mathrm{mg}$. There was no confounding of tissue biopsy weight with drug concentration. For seminal plasma, FTC and TFV QCs had accuracies of $98.3 \pm 5.6$ and $92.5 \pm 4.6$. Blood plasma FTC and TFV QCs had accuracies of $107.8 \pm 8.3$ and $98.4 \pm 7.9$. Cervicovaginal fluid FTC and TFV QCs had accuracies of 100.5 \pm 4.2 and $104.1 \pm 5.4$. The $\%$ RSD for the standards ranged from 10.3 to $4.0 \%$. The $\%$ RSD for the QCs ranged from 12.3 to $4.1 \%$.

\section{Data analysis}

PK parameters were estimated with noncompartmental methods (Phoenix WinNonlin, Pharsight). We imputed those concentrations that were detectable but below the limit of quantification as $50 \%$ of the lower limit of quantification for that analyte and matrix. Concentrations that were below the limit of detection were imputed as " 0. " The $\mathrm{AUC}_{1-14 \mathrm{~d}}$ after dose was estimated with the log-linear trapezoidal method, and visual curve stripping was performed for estimation of the terminal elimination slope. Individual PK profiles were obtained for blood plasma, cervicovaginal fluid, and seminal plasma. A composite approach was used to estimate tissue PK parameters by analyzing geometric mean concentration data. To compare cervicovaginal fluid, seminal plasma, and tissue exposure to blood plasma, we calculated $C_{24 \mathrm{~h}}$ and $\mathrm{AUC}_{1-14 \mathrm{~d}}$ ratios. A tissue density of $1.04 \mathrm{~g} / \mathrm{ml}$ was used to convert $\mathrm{ng} / \mathrm{g}$ to $\mathrm{ng} / \mathrm{ml}$ for this purpose (33). We generated descriptive statistics using WinNonlin. Demographic data and PK parameters are presented as median values (25th to 75th percentile).

\section{Acknowledgments}

We gratefully acknowledge the assistance of R. Madanick, E. Dellon, and I. Grimm in performing flexible sigmoidoscopies at the UNC Healthcare Meadowmont Gastrointestinal Clinic. Urine sexually transmitted disease screening was performed in the Microbiology Core Laboratory of the Southeastern Sexually Transmitted Infections Cooperative Research Center under the direction of M. Hobbs (NIH grant U19 AI31496). We also appreciate T. Stevens for his editorial assistance.

Funding: This work was supported in part by NIH grants R37 DK49381 (M.S.C.), R34 AI087065 (A.D.M.K.), K23 AI77355 (K.B.P.), P30 AI50410 (UNC Center for AIDS Research), and UL1 RR025747 (UNC TraCS Clinical Translational Research Center) and the Gilead Sciences Investigator Initiated Research Program.

\section{REFERENCES AND NOTES}

1. UNAIDS. [[accessed 14 December 2010].] Report on the Global AIDS Epidemic. 2010. http:// www.unaids.org/documents/20101123_GlobalReport_em.pdf

2. Donnell D, Baeten JM, Kiarie J, Thomas KK, Stevens W, Cohen CR, McIntyre J, Lingappa JR, Celum C. Partners in Prevention HSV/HIV Transmission Study Team, Heterosexual HIV-1 
transmission after initiation of antiretroviral therapy: A prospective cohort analysis. Lancet. 2010; 375:2092-2098. [PubMed: 20537376]

3. Panel on the Treatment of HIV-Infected Pregnant Women and Prevention of Perinatal Transmission. [[accessed 14 December 2010].] Recommendations for Use of Antiretroviral Drugs in Pregnant HIV-1 Infected Women for Maternal Health and Interventions to Reduce Perinatal HIV Transmission in the United States. May 24. 2010 p. 1-117;.http://www.aidsinfo.nih.gov/Guidelines/ GuidelineDetail.aspx

4. Abdool Karim Q, Abdool Karim SS, Frohlich JA, Grobler AC, Baxter C, Mansoor LE, Kharsany AB, Sibeko S, Mlisana KP, Omar Z, Gengiah TN, Maarschalk S, Arulappan N, Mlotshwa M, Morris L, Taylor D. CAPRISA 004 Trial Group. Effectiveness and safety of tenofovir gel, an antiretroviral microbicide, for the prevention of HIV infection in women. Science. 2010; 329:11681174. [PubMed: 20643915]

5. Grant RM, Lama JR, Anderson PL, McMahan V, Liu AY, Vargas L, Goicochea P, Casapía M, Guanira-Carranza JV, Ramirez-Cardich ME, Montoya-Herrera O, Fernández T, Veloso VG, Buchbinder SP, Chariyalertsak S, Schechter M, Bekker LG, Mayer KH, Kallás EG, Amico KR, Mulligan K, Bushman LR, Hance RJ, Ganoza C, Defechereux P, Postle B, Wang F, McConnell JJ, Zheng JH, Lee J, Rooney JF, Jaffe HS, Martinez AI, Burns DN, Glidden DV. iPrEx Study Team, Preexposure chemoprophylaxis for HIV prevention in men who have sex with men. N Engl J Med. 2010; 363:2587-2599. [PubMed: 21091279]

6. Kashuba, A.; Abdool Karim, SS.; Kraft, E.; White, N.; Sibeko, S.; Werner, L.; Mansoor, L.; Gengiah, T.; Sidhoo, S.; Naranbhai, V.; Abdool Karim, Q. Do systemic and genital tract tenofovir concentrations predict HIV seroconversion in the CAPRISA 004 tenofovir gel trial?. paper presented at the XVIII International AIDS Conference; Vienna, Austria. 18 to 23 July 2010;

7. Anderson, P.; Lama, J.; Buchbinder, S.; Guanira, J.; Montoya, O.; Casapia, M.; Bragg, L.; Bushman, L.; Glidden, D.; Grant, R. Interpreting detection rates of intracellular FTC-TP and TFVDP: The iPrEx trial. paper presented at the 18th Conference on Retroviruses and Opportunistic Infections; Boston, MA. 27 February to 2 March 2011;

8. Thigpen, M.; Kebaabetswe, P.; Smith, D.; Segolodi, T.; Soud, F.; Chillag, K.; Chirwa, LI.; Kasonde, M.; Mutanhaurwa, R.; Henderson, FL.; Pathak, S.; Gvetadze, R.; Rose, CE.; Paxton, LA. Daily oral antiretroviral use for the prevention of HIV infection in heterosexually active young adults in Botswana: Results from the TDF2 study. paper presented at the 6th International AIDS Society Conference; Rome, Italy. 17 to 20 July 2011 ;

9. Baeton, J.; Celum, C. Antiretroviral pre-exposure prophylaxis for HIV-1 prevention among heterosexual African men and women: The Partners PrEP Study. paper presented at the 6th International AIDS Society Conference; Rome, Italy. 17 to 20 July 2011;

10. FHI360. [[accessed 2 August 2011].] FEM-PrEP Project;. http://www.fhi.org/en/Research/Projects/ FEM-PrEP.htm

11. [[accessed 6 October 2011].] NIH modifies 'VOICE' HIV prevention study in women;. http:// www.nih.gov/news/health/sep2011/niaid-28.htm

12. Blum MR, Chittick GE, Begley JA, Zong J. Steady-state pharmacokinetics of emtricitabine and tenofovir disoproxil fumarate administered alone and in combination in healthy volunteers. J Clin Pharmacol. 2007; 47:751-759. [PubMed: 17519400]

13. Dumond JB, Yeh RF, Patterson KB, Corbett AH, Jung BH, Rezk NL, Bridges AS, Stewart PW, Cohen MS, Kashuba AD. Antiretroviral drug exposure in the female genital tract: Implications for oral pre- and post-exposure prophylaxis. AIDS. 2007; 21:1899-1907. [PubMed: 17721097]

14. Cohen MS, Gay C, Kashuba AD, Blower S, Paxton L. Narrative review: Antiretroviral therapy to prevent the sexual transmission of HIV-1. Ann Intern Med. 2007; 146:591-601. [PubMed: 17438318]

15. García-Lerma JG, Otten RA, Qari SH, Jackson E, Cong ME, Masciotra S, Luo W, Kim C, Adams DR, Monsour M, Lipscomb J, Johnson JA, Delinsky D, Schinazi RF, Janssen R, Folks TM, Heneine W. Prevention of rectal SHIV transmission in macaques by daily or intermittent prophylaxis with emtricitabine and tenofovir. PLoS Med. 2008; 5:e28. [PubMed: 18254653]

16. Subbarao S, Ramos A, Kim C, Adams D, Monsour M, Butera S, Folks T, Otten RA. Direct stringency comparison of two macaque models (single-high vs. repeat-low) for mucosal HIV 
transmission using an identical anti-HIV chemoprophylaxis intervention. J Med Primatol. 2007; 36:238-243. [PubMed: 17669212]

17. Veazey RS, Klasse PJ, Schader SM, Hu Q, Ketas TJ, Lu M, Marx PA, Dufour J, Colonno RJ, Shattock RJ, Springer MS, Moore JP. Protection of macaques from vaginal SHIV challenge by vaginally delivered inhibitors of virus-cell fusion. Nature. 2005; 438:99-102. [PubMed: 16258536]

18. García-Lerma JG, Cong ME, Mitchell J, Youngpairoj AS, Zheng Q, Masciotra S, Martin A, Kuklenyik Z, Holder A, Lipscomb J, Pau CP, Barr JR, Hanson DL, Otten R, Paxton L, Folks TM, Heneine W. Intermittent prophylaxis with oral Truvada protects macaques from rectal SHIV infection. Sci Transl Med. 2010; 2:14ra4.

19. Ganor Y, Bomsel M. HIV-1 transmission in the male genital tract. Am J Reprod Immunol. 2011; 65:284-291. [PubMed: 21114566]

20. Gomes NA, Laud A, Pudage A, Joshi SS, Vaidya VV, Tandel JA. Validated LC-MS/MS method for determination of Alverine and one of its hydroxy metabolites in human plasma along with its application to a bioequivalence study. J Chromatogr B Analyt Technol Biomed Life Sci. 2009; 877:197-206.

21. D’Avolio A, Sciandra M, Siccardi M, Baietto L, Gonzalez de Requena D, Bonora S, Di Perri G. A new assay based on solid-phase extraction procedure with LC-MS to measure plasmatic concentrations of tenofovir and emtricitabine in HIV infected patients. J Chromatogr Sci. 2008; 46:524-528. [PubMed: 18647474]

22. Vourvahis M, Tappouni HL, Patterson KB, Chen YC, Rezk NL, Fiscus SA, Kearney BP, Rooney JF, Hui J, Cohen MS, Kashuba AD. The pharmacokinetics and viral activity of tenofovir in the male genital tract. J Acquir Immune Defic Syndr. 2008; 47:329-333. [PubMed: 18197124]

23. Gilead Sciences. TRUVADA (emtricitabine/tenofovir disoproxil fumarate) tablets package insert. Gilead Sciences; Foster City, CA: 2009.

24. Hawkins T, Veikley W, St Claire RL III, Guyer B, Clark N, Kearney BP. Intracellular pharmacokinetics of tenofovir diphosphate, carbovir triphosphate, and lamivudine triphosphate in patients receiving triple-nucleoside regimens. J Acquir Immune Defic Syndr. 2005; 39:406-411. [PubMed: 16010161]

25. Patterson, KB.; Prince, HA.; Kraft, E.; Jones, A.; Paul, S.; Shaheen, NJ.; Spacek, M.; Heidt, PE.; Reddy, S.; Rooney, JF.; Dumond, JB.; Cohen, MS.; Kashuba, AD. Exposure of extracellular and intracellular tenofovir and emtricitabine in mucosal tissues after a single of fixed-dose TDF/FTC: Implications for pre-exposure HIV prophylaxis. paper presented at the XVIII International AIDS Conference; Vienna, Austria. 18 to 23 July 2010;

26. Anton, P.; Cranston, R.; Carballo-Diegue, A.; Kashuba, A.; Khanukhova, E.; Elliott, J.; Janocko, L.; Cumberland, W.; Mauck, C.; McGowan, I. RMP-02/MTN-006: A phase 1 placebo-controlled trial of rectally applied $1 \%$ vaginal TFV gel with comparison to oral TDF. paper presented at the 18th Conference on Retrovirus and Opportunistic Infections; Boston, MA. 28 February to 2 March 2011;

27. Hendrix, C.; Minnis, A.; Guddera, V.; Riddler, S.; Salata, R.; Nakabiito, C.; Hoesley, C.; Justman, J.; Soto-Torres, L.; Richardson, B. MTN-001: A phase 2 cross-over study of daily oral and vaginal TFV in healthy, sexually active women results in significantly different product acceptability and vaginal tissue drug concentrations. paper presented at the 18th Conference on Retrovirus and Opportunistic Infections; Boston, MA. 28 February to 2 March 2011;

28. Denton PW, Estes JD, Sun Z, Othieno FA, Wei BL, Wege AK, Powell DA, Payne D, Haase AT, Garcia JV. Antiretroviral pre-exposure prophylaxis prevents vaginal transmission of HIV-1 in humanized BLT mice. PLoS Med. 2008; 5:e16. [PubMed: 18198941]

29. Subbarao S, Otten RA, Ramos A, Kim C, Jackson E, Monsour M, Adams DR, Bashirian S, Johnson J, Soriano V, Rendon A, Hudgens MG, Butera S, Janssen R, Paxton L, Greenberg AE, Folks TM. Chemoprophylaxis with tenofovir disoproxil fumarate provided partial protection against infection with simian human immunodeficiency virus in macaques given multiple virus challenges. J Infect Dis. 2006; 194:904-911. [PubMed: 16960777]

30. Cohen MS, Shaw GM, McMichael AJ, Haynes BF. Acute HIV-1 infection. N Engl J Med. 2011; 364:1943-1954. [PubMed: 21591946] 
31. Karim SS, Kashuba AD, Werner L, Karim QA. Drug concentrations after topical and oral antiretroviral pre-exposure prophylaxis: Implications for HIV prevention in women. Lancet. 2011; 378:279-281. [PubMed: 21763939]

32. Kwara A, DeLong A, Rezk N, Hogan J, Burtwell H, Chapman S, Moreira CC, Kurpewski J, Ingersoll J, Caliendo AM, Kashuba A, Cu-Uvin S. Antiretroviral drug concentrations and HIV RNA in the genital tract of HIV-infected women receiving long-term highly active antiretroviral therapy. Clin Infect Dis. 2008; 46:719-725. [PubMed: 18220480]

33. Mardirossian G, Tagesson M, Blanco P, Bouchet LG, Stabin M, Yoriyaz H, Baza S, Ljungberg M, Strand SE, Brill AB. A new rectal model for dosimetry applications. J Nucl Med. 1999; 40:15241531. [PubMed: 10492375] 

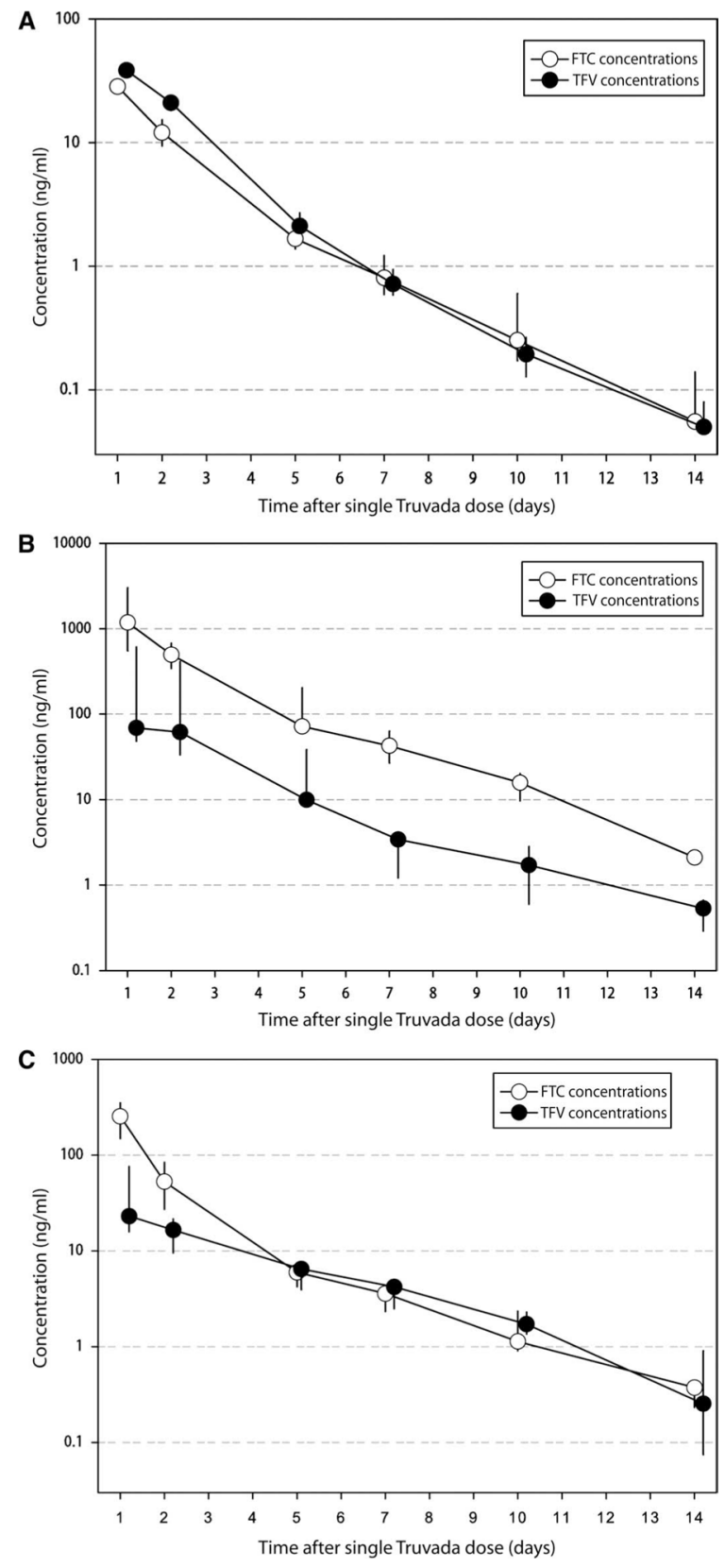

Fig. 1.

Concentrations of TFV and FTC in blood plasma, cervicovaginal fluid, and semen. (A to C) Median concentrations ( $\mathrm{ng} / \mathrm{ml}$ ) of the ART drugs TFV and FTC in (A) blood plasma, (B) cervicovaginal fluid, and (C) seminal plasma for 14 days after a single dose of a TDF/FTC drug combination (vertical lines representing interquartile ranges). Samples were analyzed by liquid chromatography and mass spectroscopy methods. 

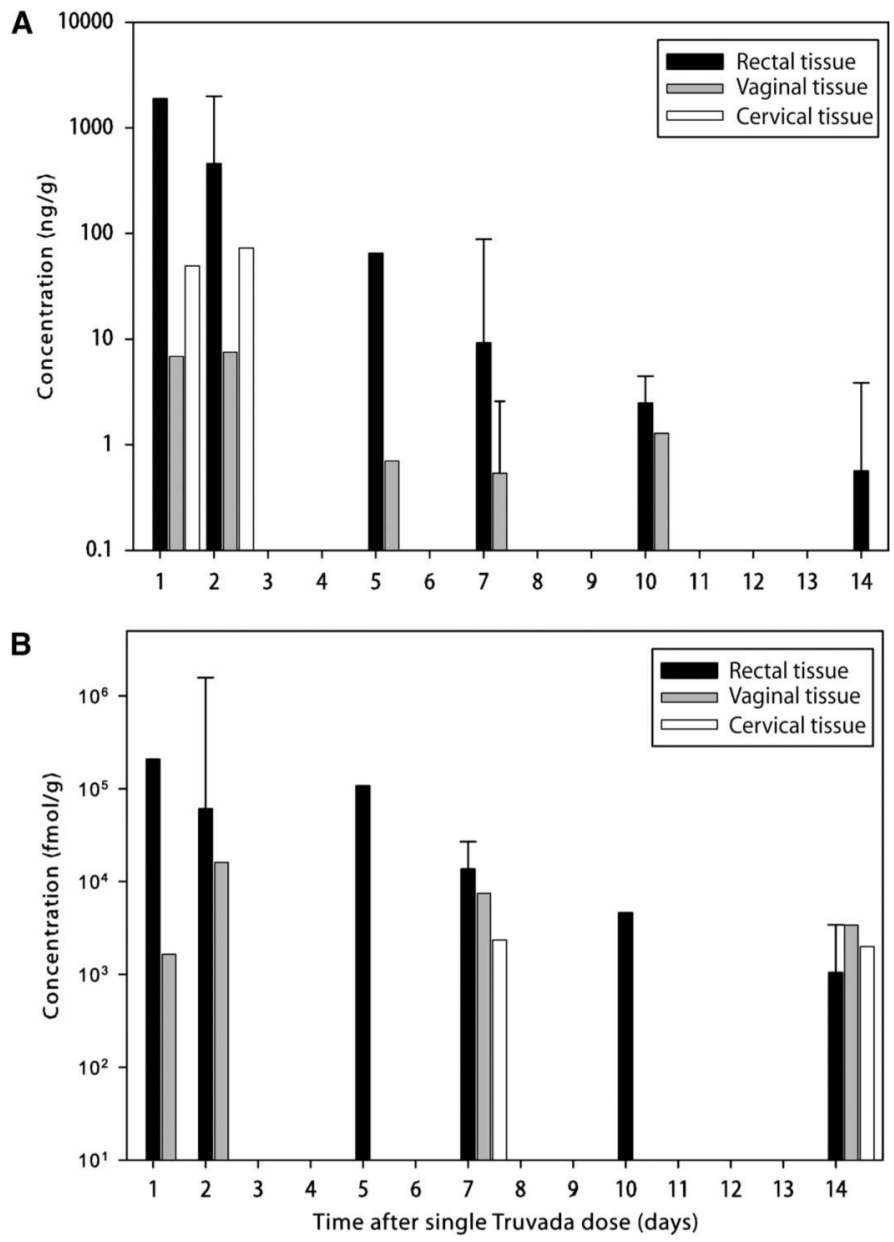

Fig. 2.

Concentrations of TFV and TFV-DP in mucosal tissues. (A and B) Median concentrations of (A) TFV (ng/g) and (B) TFV-DP (fmol/g) in rectal (black), vaginal (gray), and cervical (white) mucosal tissues over 14 days after a single dose of TDF/FTC (vertical lines represent interquartile ranges). Samples were analyzed by liquid chromatography and mass spectroscopy methods. 

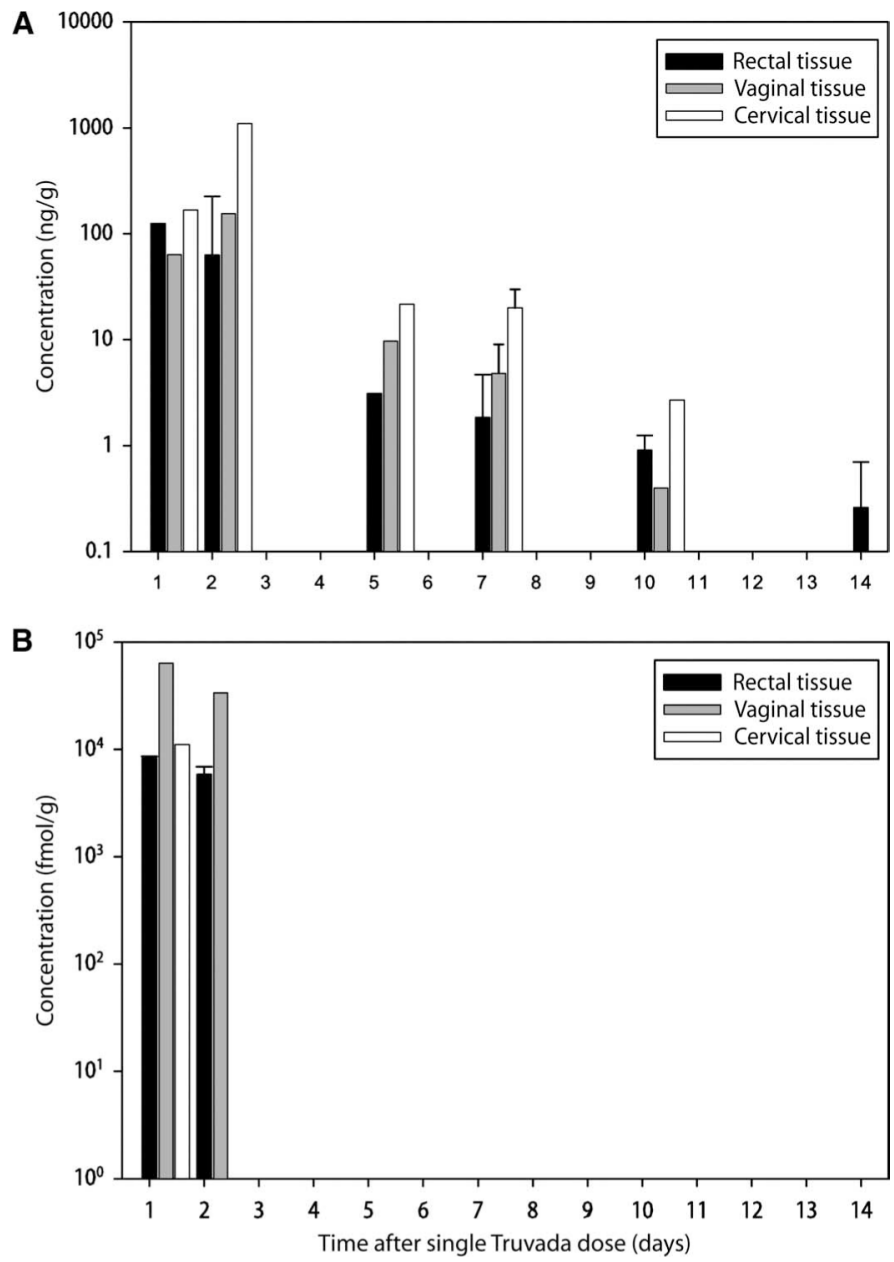

Fig. 3 .

Concentrations of FTC and FTC-TP in mucosal tissues. (A and B) Median concentrations of (A) FTC (ng/g) and (B) FTC-TP (fmol/g) in rectal (black), vaginal (gray), and cervical (white) mucosal tissues over 14 days after a single dose of TDF/FTC (vertical lines represent interquartile ranges). Samples were analyzed by liquid chromatography and mass spectroscopy methods. 


\section{Table 1}

Demographics of study participants.

\begin{tabular}{lcc}
\hline Parameter & Males $(\boldsymbol{n}=\mathbf{8})$ & Females $(\boldsymbol{n}=\mathbf{7})$ \\
\hline Age (years) & $26(19-37)$ & $22(21-25)$ \\
Race & & \\
African American & $1(12 \%)$ & $1(14 \%)$ \\
Asian & $2(25 \%)$ & 0 \\
White & $5(63 \%)$ & $6(86 \%)$ \\
Weight $(\mathrm{kg}){ }^{*}$ & $74.6(65-88.9)$ & $71.2(61.4-87.8)$ \\
BMI $\left(\mathrm{kg} / \mathrm{m}^{2}\right)^{*}$ & $23.5(18.8-28.1)$ & $24.8(21.2-28.6)$ \\
\hline$*$ & & \\
Median (range). & &
\end{tabular}




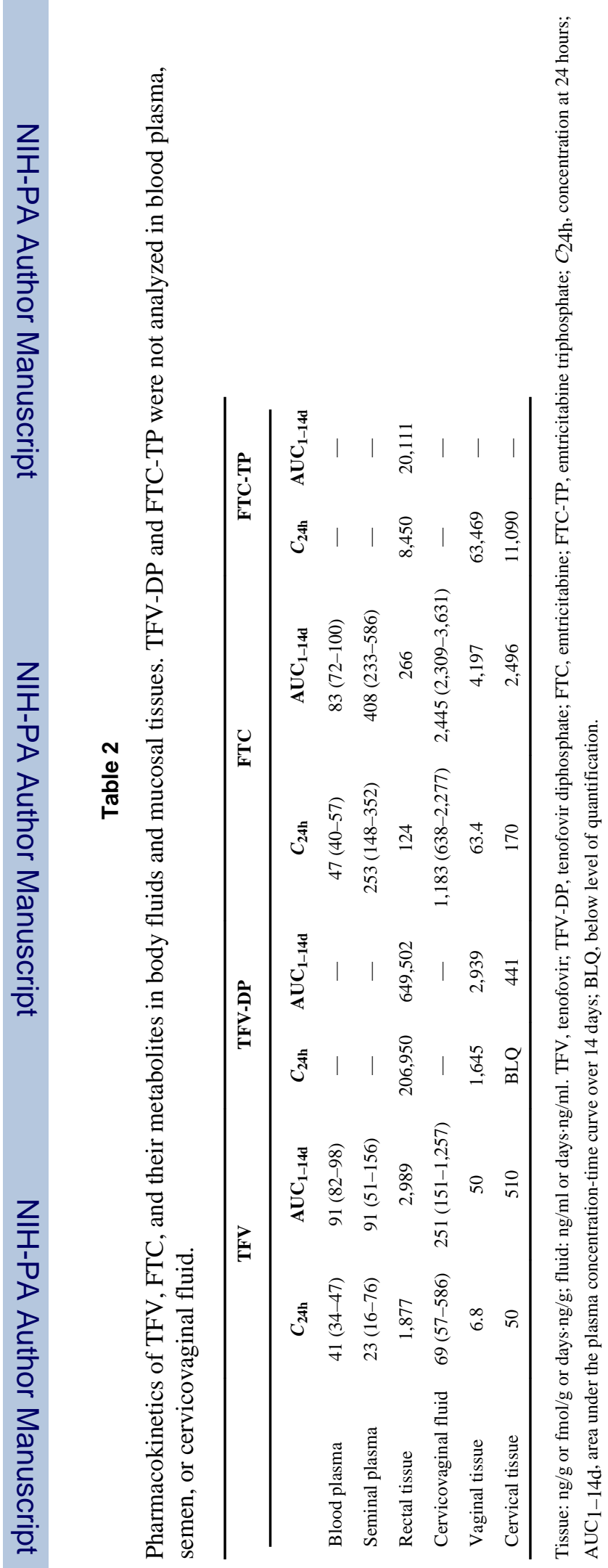

